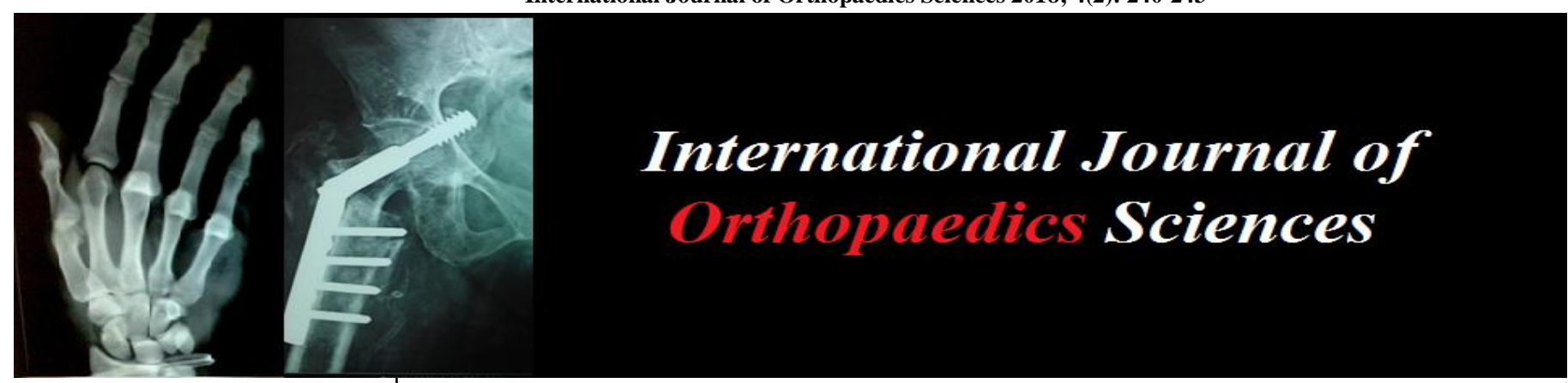

ISSN: $2395-1958$

IJOS 2018; 4(2): 240-243

(C) 2018 IJOS

www.orthopaper.com

Received: 16-02-2018

Accepted: 19-03-2018

Dr. Raghavendra MS MS, Senior Resident, Department of Orthopaedics, Chamarajanagar Institute of Medical Sciences
Correspondence

Dr. Raghavendra MS MS, Senior Resident, Department of Orthopaedics, Chamarajanagar Institute of Medical Sciences

\section{Study of effectiveness of interlocking nail in management of fracture shaft humerus}

\section{Dr. Raghavendra MS}

DOI: https://doi.org/10.22271/ortho.2018.v4.i2d.37

\section{Abstract}

Background \& Objectives: Operative management of humeral shaftfractures can be with plate osteosynthesis or with intramedullary nailing. As the intramedullary nails can be introduced in a closed manner, they preserve the fracture hematoma, providing early fracture consolidation with higher union rates and low infection rates. Interlocking achieves rotational stability providing early mobilization of the neighbouring joints. But, with antegrade nailing they do have a disadvantage of causing shoulder stiffness.

In this study we have tried to analyze the outcome in terms of time for consolidation, union rates, functional results and complications of humeral shaft fractures managed with intramedullary nailing.

Methods: 20 adult patients with acute humeral shaft fractures were treated withclosed intramedullary nailing in antegrade manner. There were 15 males and 5 females with an average age of 35.75 years (2160 years). All the patients were followed over a period of 2 years and results were analyzed.

Results: 17 (85\%) fractures united with a average consolidation time of 13.5 weeks (10-16 weeks), $2(10 \%)$ fracture ended in delayed union which needed bone grafting. $1(5 \%)$ case needed redoing with plate osteosynthesis due to severe nail prominence. There was no case of iatrogenic radial nerve palsy. Nail impingement was seen in $4(20 \%)$, shoulder stiffness in $1(5 \%)$ and none of the patients got infected. Functional results were excellent in $15(75 \%)$, moderate in $4(20 \%)$ and poor in $1(5 \%)$.

Conclusion: Closed intramedullary nailing offers a safe and reliable method offixing humeral shaft fractures, with early fracture consolidation and higher union rates. It provides early rehabilitation and reduces the hospital stay.

Keywords: Study of effectiveness, interlocking nail, fracture shaft humerus

\section{Introduction}

It is generally admitted that most humeral shaft fractures can be managed successfully by nonoperative methods. Whenever operative treatment is required, a choice has to be made between plate osteosynthesis and intramedullary nailing.

Fixation with plates requires extensive dissection and is complicated by the proximity of the radial nerve and the risk of mechanical failure in osteopenic bones.Biomechanically intramedullary nail is a better implant. They are subjected to smaller bending loads and are less likely to fail by fatigue, they act as load sharing devices, stress shielding with resultant cortical osteopenia is minimum, refracture after implant removal is rare and they do not require extensive exposure 1 .

With the use of image intensification, these devices can be inserted in a closed manner without exposing the fracture site, with minimal soft tissue scaring and low infection rates. This preserves the fracture hematoma, which provides early fracture consolidation with higher union rates. With interlocking mechanism they achieve rotational stability and provide early mobilization of the neighbouring joints and decrease the morbidity. Due to reduced hospital stay and early return of the patient to his job, financial burden on the family is less. Keeping all these aspects in mind, we took up this study to assess the role of intramedullary nailing with a introlocking nail in managing humeral shaft fractures.

\section{Aim of Study}

- To study the fractures of humeral shaft. 
- To study the mechanism of injury in humeral shaft fractures.

- To assess the advantages and disadvantages, of closed intramedullary nailing in anaging humeral shaft fractures.

- To study the pitfalls and complications of the nailing technique in managing humeral shaft fractures.

- To analyze the outcome in terms of period of fracture consolidation, union rates and functional results of humeral shaft fractures managed by intramedullary nailing.

\section{Materials and Methods}

Our study is a series of 20 cases of acute humeral shaft fractures treated with closed intramedullary interlocking nailing. This study was conducted over a period of 2 years from July 2013 to June 2015.

\section{Inclusion Criteria}

- Patients were selected based upon following criterias

- $\quad$ Age more than 17 years, when the physis is fused.

- Fractures of humeral shaft from $3 \mathrm{~cm}$ proximal to the olecranon fossa to within $2 \mathrm{~cm}$ of the surgical neck of the humerus.

- Closed fractures and grade I open fractures.

\section{Exclusion Criteria}

- Patients aged 17 years or below, when the physis is open.

- Humeral shaft fractures involving the proximal $2 \mathrm{cms}$ and distal $3 \mathrm{cms}$ of the humerus.

- Grossly contaminated, open fractures - Grade II, III

A careful history was elicited from the patients and / or attenders to reveal the mechanism of injury and the severity of trauma. The patients were then assesed clinically to evaluate there general condition and local injury. The vital signs were recorded and associated injuries were carefully assesed.

Local examination was carried out to detect the signs of fracture like, swelling, deformity, tenderness, abnormal mobility and crepitus. Any associated neurovascular deficit was noted.

Radiographs of the affected arm including shoulder and elbow joints were taken in antero-posterior and lateral views. The limb was immobilised in a U-slab with collar and cuff sling and analgesics were given.

The operative procedure, its advantages and likely complications were explained to the patient and informed consent was obtained. All the necessary blood investigations (complete blood count, blood urea, serum creatinine, blood sugur, HIV, HBSAg), ECG and if necessary chest X-ray were taken. Physicians fitness for surgery was obtained.

All the cases were treated by intramdullary interlocking nailing in antegrade manner

Postoperatively, the arm is placed in a sling and early range of motion excercises for shoulder and elbow were started as discomfort subsided, usually on

5 th or 6th postoperative day. Shoulder range of motion excercise is emphasized to avoid stiffness. In patients where there were no associated injuries or there presence did not warrant hospital stay, after instructing regarding range of motion excercises patients were discharged on 4th or 5th postoperative day and were asked to come for suture removal on 12 th postoperative day.

\section{Follow up}

All the patients were followed up at monthly intervals for the first 3 months, later on 2 monthly interval till fracture union and once in 6 months till the completion of study. Special stress is laid on shoulder and elbow range of movements and subjective complaints. Radiographs were taken both in anteroposterior and lateral views and signs of union were looked for.

\section{Assessment of Results}

Assessment of the patient was done on the basis of clinical and radiological union, range of motion at shoulder and elbow joints and subjective complaints like pain in shoulder / elbow. Functional results were graded by the criteria of Rommens et al. ${ }^{[21]}$. Shoulder and elbow functions were graded excellent, moderate or poor depending upon the loss of range of motion in any direction, subjective complaints like pain was also taken into account.

\begin{tabular}{|c|c|c|}
\hline Grade & Range of motion (ROM) & Subjective \\
\hline & (Shoulder/elbow) & compliants \\
\hline Excellent & $<10^{0}$ loss of ROM in any direction & None \\
\hline Moderate & Loss of ROM between $10^{0}$ to $30^{0}$ in & \\
\hline & any direction & Mild \\
\hline Poor & Loss of ROM $>30^{0}$ in any direction & Moderate toSever \\
\hline
\end{tabular}

The total functional out come at the time of review took both joints (shoulderand elbow) into account.

\section{Results}

\section{Observations and Results}

The present study consists of 20 cases of humeral shaft fracture treated by closed intramedullary nailing by antegrade method. The study is conducted over a period of two years between July 2013 to June 2015. All the patients were available for follow up.

\section{Following observations were made}

Our patient's age range from 21 years to 75 years with an average of 23.5 years. 12 male and 8 female patients. Right side commonly affected.

\section{Type of Fracture}

18 were closed fractures and 2 were grade-I open fractures. All the fractures were classified according to AO classification system

\section{Fracture Union}

Period of fracture union ranged from 10 to 16 weeks, average period being 13.5 weeks.

Table I

\begin{tabular}{|c|c|c|}
\hline Period of Union & No. of Patients & Percentage \\
\hline 10 to 12 weeks & 15 & 75 \\
\hline 13 to 16 weeks & 4 & 20 \\
\hline Non-union & 1 & 5 \\
\hline
\end{tabular}

\section{Functional Assessment}

Functional results were graded by the criteria of Rommens et $a l .{ }^{[21]}$. Shoulder and elbow functions were graded excellent, moderate or poor depending upon the loss of range of motion in any direction, subjective complaints like pain was also taken into account. 
Table II

\begin{tabular}{|c|c|c|c|c|c|c|}
\hline \multicolumn{7}{|c|}{ Shoulder and elbow function } \\
\hline Grade & Shoulder & Elbow & & \multicolumn{2}{c|}{ Total Outcome } \\
\hline & No & $\mathbf{\%}$ & No & \% & No & $\%$ \\
\hline Excellent & 15 & 75 & 20 & 100 & 15 & 75 \\
\hline Moderate & 4 & 20 & 0 & 0 & 4 & 20 \\
\hline Poor & 1 & 5 & - & - & 1 & 5 \\
\hline
\end{tabular}

In most of the patients functional outcome was satisfactory. Restriction of joint motion was seen in patients who didn't followed physiotheraphy properly.

Table III: Complications

\begin{tabular}{|c|c|c|}
\hline Complications & $\begin{array}{c}\text { No. of } \\
\text { Patients }\end{array}$ & Percentage \\
\hline Non-union & 1 & 5 \\
\hline Transient Iatrogenic Radial nerve palsy & 0 & 0 \\
\hline Shoulder stiffness & 1 & 5 \\
\hline Nail Impingement & 4 & 20 \\
\hline
\end{tabular}

\section{Conclusion}

Based on our experience and results we conclude that closed intramedullary nailing with a interlocking nail is a safe and reliable method of treating humeral shaft fractures.

- Essentially all closed and Grade I open humeral shaft fractures extending between $2 \mathrm{~cm}$ from surgical neck to 3 cms proximal to the olecrenon fossa can be stabilized with closed intramedullary nailing.

- It is excellent mode of managing communited and unstable humeral shaft fractures.

- It is the best surgical method available to fix humeral shaft fractures in patients with polytrauma and osteoporosis where reduction in operating time and early rehabilitation are the primary objectives.

- In available surgical modalitis, closed nailing is the least invasive surgical technique and has got the least chance of postoperative infection. It reduces the hospital stay.

- Since closed nailing preserves the fractures hematoma, it appreciably decreases the time required for fracture to consolidate and achives high rate of fracture union.

- Complications like non-union can be avoided by intraoperative compression and avoiding distraction at fracture site.

- Certain technical aspects like burying the proximal nail end at the entry portal are essential in avoiding impingement and to gain better shoulder function.

- We think that early intensive physical theraphy hastens the recovery of shoulder function.

- In short, closed nailing is an excellent least invasive surgical option available to manage humeal shaft fractures with early fracture consolidation and better union rates. It decreases the hospital stay, provides early rehabilitation and lessens the morbidity. It is ideal in patients with polytrauma and osteoporosis.
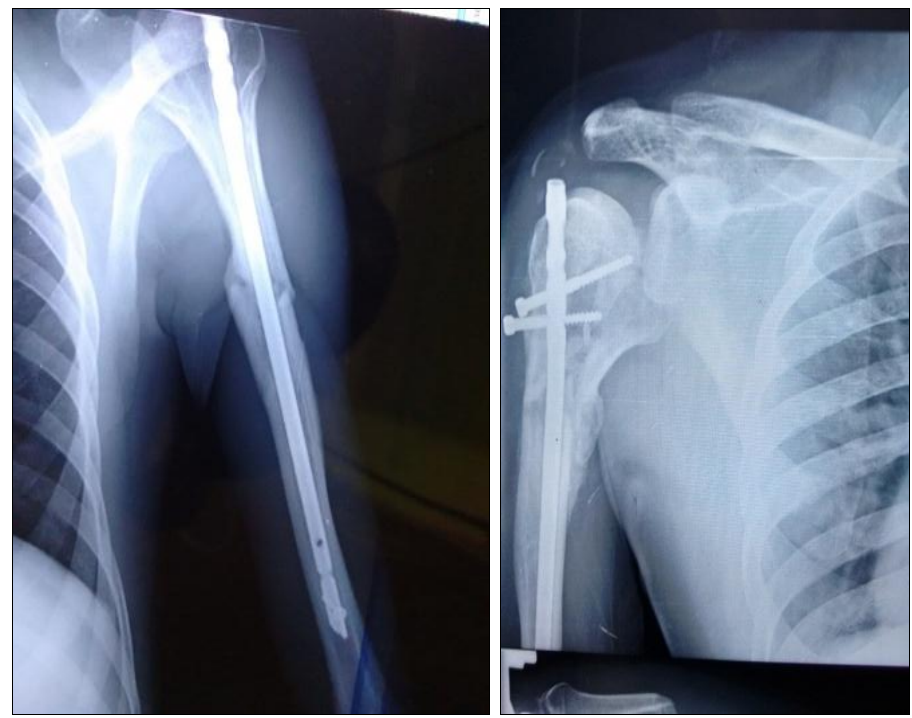

Post Op Images

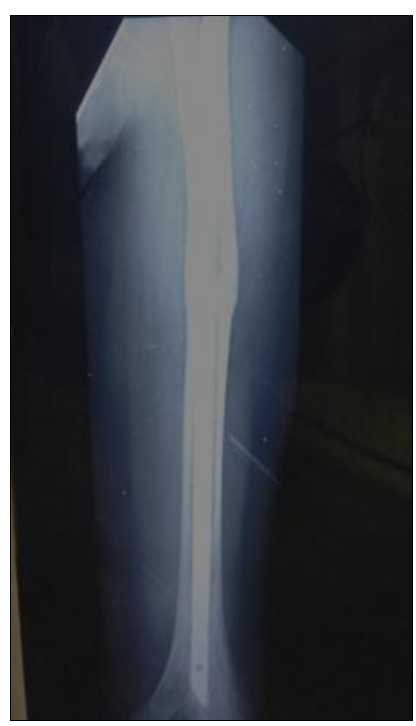

stacked nailingof humeral shaft fractures : Experineces with 30 patients. Clin Orthop. 1983; 179:168-174.

\section{References}

1. Crates J, Whittle AP. Antegrade interlocking nailing of acute humeral shaftfractures. J Clinic Orthop 1998; 350: 40-50.

2. Tingstad EM. Effect of immediate weight bearing on plated fractures ofthe humeral shaft. J Trauma. 2001; 49(2):278-280.

3. Vander Griend R, Tomasin J, Ward EF. Open reduction and internal fixationof humeral shaft fractures : Results using AO plating techniques. J Bone Joint Surg. 1986; 68A:430-433.

4. Dabezies EJ, Banta II CJ, Mruphy CP, d'Ambrosia KD. Plate fixation of thehumeral shaft for acute fractures. with and without radial nerve injuries. J Orthop Trauma. 1992; 6:10-13.

5. Durbin RA, Gottesman MJ, Sanders KC. Hackethal
6. Riemer BL, Butterfield SL, D'Ambrosia R, Kellam J. Seidel intramedullarynailing of humeral diaphyseal fractures: A preliminary report. Orthopaedics. 1991; 14:239-246.

7. Jensen $\mathrm{CH}$, Hansen D, Jorgensen U. Humeral shaft fractures treated byinterlocking nailing. A priliminary report on 16 patients. Injury 1992; 23(4):234-236.

8. Rodriguez, Merchan EC. Compression plating versus Hackethal nailing inclosed humeral shaft fractures failing nonoperative reduction. J Orthop Trauma. 1995; 9:194197.

9. Foster RJ, Dixon Jr. GL, Back AW. Internal fixation of fractures andnon unions of the humeral shaft : Indications and results in a multicenter study. J Bone Joint Surg. 
1985; 67A:857-864.

10. Pogliacomi F, Devecchi A, Costantino C. Vaienti EFunctional long-term outcome of the shoulder after antegrade intramedullary nailing in humeral diaphyseal fractures.Chir Organi Mov. 2008; 92(1):11-6. doi: 10.1007/s12306-008-0035-6. Epub 2008 Mar 1

11. Virkus WV, Goldberg SH, Lorenz EP. A comparison of compressive force generation by plating and intramedullary nailing techniques in a transverse diaphyseal humerus fracture model. J Trauma. 2008; 65(1):103-8. doi: 10.1097/TA.0b013e3181568ce7

12. Lekic N, Montero NM, Takemoto RC, Davidovitch RI, Egol KA. Treatment of two-part proximal humerus fractures: intramedullary nail compared to locked plating HSS J. 2012; 8(2):86-91. doi: 10.1007/s11420-012-9274-z. pub 2012 May 12.

13. Kloub M, Holub K, Kopačka P, Džupa V. Long-term results of nailing of extra-articular proximal humerus fractures Acta Chir Orthop Traumatol Cech. 2013; 80(3):203-7

14. Türken MA, Akdemir M, Uzun B, Ozkan M. Acta Orthop Traumatol Turc. Biomechanical evaluation of different internal fixation methods for humerus shaft fractures with medial butterfly fragment. 2013; 47(3):173-8

15. Hatzidakis AM, Shevlin MJ, Fenton DL, Curran-Everett D, Nowinski RJ, Fehringer EV. J Bone Joint Surg Am. Angular-stable locked intramedullary nailing of twopart surgical neck fractures of the proximal part of the humerus. A multicenter retrospective observational study, 2011, 93 